\title{
Pre-calculated LCI systems with uncertainties cannot be used in comparative LCA
}

\author{
Reinout Heijungs $^{1,2}$ (D) • Patrik J. G. Henriksson ${ }^{3,4}$ • Jeroen B. Guinée ${ }^{2}$
}

Received: 20 December 2016/Accepted: 11 January 2017 / Published online: 17 January 2017

(C) Springer-Verlag Berlin Heidelberg 2017

A recent paper by Qin and Suh (2016) provides an interesting test of the assumption of lognormally distributed life cycle inventory (LCI) results.

We appreciate the importance of this work, and acknowledge that finding out this result must have taken a long computation time. In that respect, we would like to comment on the remark in section 4 that "conducting uncertainty analysis from the unit process level is neither time-efficient nor necessary for most studies. Therefore, the determination of the distribution that best fits the aggregate LCI is needed. It would help improve the efficiency of storing uncertainty data and performing uncertainty analysis in life cycle analysis (LCA) by saving computation and storage of LCI data." The authors further illustrate this alleged advantage by an example where computation is reduced from $1000 \mathrm{~min}$ to $15 \mathrm{~s}$.

This would be great indeed, but the unfortunate fact is that this will not work for "most studies", because most studies are comparative LCAs, comparing a number of alternative product systems, or comparing an existing product system with a proposed redesign. In comparative LCA, including uncertainties in

\footnotetext{
Responsible editor: Mary Ann Curran

Reinout Heijungs

r.heijungs@vu.nl

1 Department of Econometrics and Operations Research, Vrije Universiteit Amsterdam, De Boelelaan 1105,

1081HV Amsterdam, The Netherlands

2 Institute of Environmental Sciences (CML), Department of Industrial Ecology, Leiden University, Einsteinweg 2, 2333 CC Leiden, The Netherlands

3 Stockholm Resilience Centre, 10691 Stockholm, Sweden

4 WorldFish, Jalan Batu Maung, 11960 Penang, Malaysia
}

a sampling context should be done in a dependent way (Henriksson et al. 2015), just like the effectiveness of a therapy is best tested with a paired test, as any textbook in statistics (Moore et al. 2009; Agresti and Franklin 2013) will discuss.

Using pre-calculated distributions of complete systems, as suggested by Qin and Suh (2016) will lead to a large overestimation of the uncertainty of the results of comparative LCA. Figure 2 of Henriksson et al. (2015) gives an illustration of strongly overlapping error bars when analysed as complete systems, versus a clear-cut answer with moderate error bars when considered from the point of view of dependent sampling and analysis.

Knowledge of the distribution of LCI results does not provide sufficient information for a paired comparison. The result is that each case study requires generating new Monte Carlo samples, dependently sampled and comparing results between alternative product systems for each Monte Carlo run. The gain of computing time by a factor of 4000, as envisaged by Qin and Suh (2016), will unfortunately thus not be achievable at all in comparative LCA. We must go to smarter algorithms, high performance hardware and parallel computing (Heijungs et al. 2015).

\section{References}

Agresti A, Franklin C (2013) Statistics. The art and science of learning from data. 3rd edn. Pearson, Boston

Henriksson PJG, Heijungs R, Dao HM, Phan LT, de Snoo GR, Guinée JB (2015) Product carbon footprints and their uncertainties in comparative decision context. PLoS One 10(3):e0121221

Heijungs R, de Koning A, Wegener Sleeswijk A (2015) Sustainability analysis and systems of linear equations in the era of data abundance. Journal of Environmental Accounting and Management 3: $109-122$

Moore DS, McCabe GP, Craig BA (2009) Introduction to the practice of statistics. 6th edn. W. H. Freeman and Company, New York

Qin Y, Suh S (2016) What distribution function do life cycle inventories follow? Int J Life Cycle Assess. doi:10.1007/s11367-016-1224-4 